\title{
Ontogeny of Amino Acid Reabsorption in Human Kidney. Evidence from the Homozygous Infant with Familial Renal Iminoglycinuria for Multiple Proline and Glycine Systems
}

\author{
LOREY LASLEY AND CHARLES R. SCRIVER ${ }^{130,}$ \\ Department of Pediatrics, Faculty of Medicine, Department of Biology, Faculty of Science, McGill University and \\ deBelle Laboratory for Biochemical Genetics, McGill University-Montreal Children's Hospital, Research Institute, \\ Montreal, Quebec, Canada
}

\begin{abstract}
Summary
Seven infants (two French Canadian, four Ashkenazi Jewish, and one Greek) with massive selective hyperiminoglycinuria (proline, hydroxyproline, and glycine) were detected by urine screening in the second week of life. Follow-up investigations and family studies revealed that each subject had a benign condition, f $f$ milial renal iminoglycinuria, an autosomal recessive condition.

The family studies (Table 1 and Fig. 1) indicate the presence of at least two different mutant alleles segregating in this small group of probands. Homozygotes of two forms and one genetic compound were identified.

Quantitative studies revealed normal concentrations of proline and glycine in plasma (Fig. 2), normal maturation of creatinine clearance (as an index of glomerular filtration rate) (Fig. 3), and elevated renal clearance of proline and glycine (Table 2). Fractional excretion $\left(\mathrm{C}_{\mathrm{AA}} / \mathrm{C}_{\mathrm{CR}}\right)$ of both proline and glycine in the probands was far in excess of that expected for the normal postnatal infant; $F E_{\text {Pro }}$ and $F E_{G l y}$ approached $100 \%$ of the filtered load on occasion (Fig. 4). A schedule of maturing tubular reabsorptive activity was apparent in the proband group. Proline reabsorption matured earlier than glycine reabsorption in the homozygotes (and the genetic compound) as it does in the normal infants (Fig. 5).

Our findings suggest that three gene products serve net tubular reabsorption of imino acids and glycine in human kidney. One, affected by mutation in our patients, is responsible for a shared transport activity; a second with preference for proline, and not affected by the mutation, has an "early" schedule of postnatal maturation; and a third with preference for glycine, also not affected by the mutation, has a "late" schedule of maturation.
\end{abstract}

\section{Speculation}

Ontogeny and Mendelian mutation observed together are useful probes of transport processes in epithelial structures. Deviant postnatal net reabsorption for proline and glycine is likely to reflect deviant and specific brush border membrane carrier activity toward these amino acids.

A set of transport mechanisms is believed to serve net tubular reabsorption of the iminoacids (proline and hydroxyproline) and glycine from the glomerular filtrate in man (18). Loss of a component, shared by iminoacids and glycine during reabsorption, appears to explain the otherwise benign homozygous phenotype in hereditary renal iminoglycinuria $(16,24)$. However, the mutant homozygote still possesses substantial residual net reabsorption of iminoacids and glycine under endogenous conditions. This residual activity has been taken as an indication for the presence of additional transport process(es) in the renal tubule, perhaps one with a preference for iminoacids and another with preference for glycine $(16,24)$. Since net reabsorption is determined to a great extent by brush border membrane transport activity of the proximal tubule $(19,20)$, in this instance a benign mutation appears to be a useful probe, revealing the presence of more than one transport system serving iminoacids and glycine in that membrane of tubular epithelial cells. In this report, we have used the occurrence of ontogeny and mutation together to examine this possibility further in the human infant.

\section{PATIENTS AND METHODS OF INVESTIGATION}

Seven Caucasian infants (two French-Canadian, four Ashkenazi Jewish, and one Greek), each with exceptional iminoglycinuria, were discovered in the second week of life by the urine screening program of the Quebec Network of Genetic Medicine $(10,25)$.

After follow-up qualitative studies had confirmed the presence of persistent massive iminoglycinuria, each infant was admitted, with informed consent, as a day patient to the Clinical Investigation Unit at the Montreal Children's Hospital. More than one quantitative study was performed during the first year of life in five of the patients (the probands for pedigrees $1,2,3,4$, and 6) and repeat qualitative studies were possible in six (the aforementioned probands plus proband 5). Family studies confirmed the hereditary nature of the condition in all seven probands.

For quantitative studies, a timed morning urine collection was obtained in the fasting state. Glucose-water $(5 \% \mathrm{w} / \mathrm{v})$ was offered by mouth to increase the urine flow rate during the collection period which lasted about $3 \mathrm{hr}$. Urine was voided spontaneously into a collector fitted with an alarm system to permit timed collections. A heparinized venous blood sample was drawn at the end of the urine collection period to permit calculation of the renal clearance of amino acids and creatinine. Qualitative studies were performed on random urine collections to observe the persistence of hyperiminoglycinuria.

Quantitative measurements (renal clearance of amino acids and creatinine) were obtained from seven parents, after an overnight fast with the subject remaining in the supine position following a modest waterload to enhance urine volume. Qualitative studies were performed on fasting urine samples in all patients.

The methods for preparation of plasma and urine and for qualitative (two-dimensional partition chromatography on filter paper) and quantitative (elution chromatography on ion exchange resin columns) añalysis of amino acids have been described previously $(16,21)$. Creatinine was measured in plasma and urine samples by a standard method on a Technicon autoanalyzer. Renal clearance of creatinine was used to estimate the glomerular 
filtration rate and to calculate fractional excretion of amino acids $\left(\mathrm{FE}_{\mathrm{AA}}\right)$ by the formula $\mathrm{FE}_{\mathrm{AA}}=\mathrm{C}_{\mathrm{AA}} / \mathrm{C}_{\mathrm{Cr}}=\mathrm{U}_{\mathrm{AA}} / \mathrm{F}_{\mathrm{AA}}$, where $\mathrm{U}_{\mathrm{AA}}$ $=$ urine excretion of amino acids ( $\mu$ moles $/ \mathrm{min}$ ) and $\mathrm{F}_{\mathrm{AA}}=$ the corresponding filtered load of amino acids, calculated from the equation $\mathrm{F}_{\mathrm{AA}}=\mathrm{C}_{\mathrm{Cr}} \cdot[\mathrm{AA}]_{\text {plasma }}$.

$\mathrm{C}_{\mathrm{AA}}$ and $\mathrm{C}_{\mathrm{Cr}}$ are the renal clearance of amino acid and creatinine, respectively, calculated in the usual way. All data were adjusted to a coefficient of standard body surface area $\left(1.73 \mathrm{~m}^{2}\right)$ for purposes of interindividual comparison during ontogenesis of renal function.

Formal classification of the familial iminoglycinuria genotype requires titration of the renal $T_{m}$ for proline and glycine and investigation of intestinal absorption of these amino acids (18). Such studies were not essential for our purposes; accordingly, the mutant allele is not defined. Classification is restricted to heterozygosity, homozygosity (or genetic compound), and whether the allele is completely or incompletely recessive in the heterozygote.

\section{RESULTS}

\section{CONFIRMATION OF HYPERIMINOGLYCINURIA}

Qualitative and quantitative findings confirmed the presence of persistent hyperiminoglycinuria in the seven infants. However, since hyperiminoglycinuria is also characteristic of the normal infant $(15,28)$, additional characterization of the finding was required.

\section{FAMILY STUDIES}

Family studies were used to confirm the presence of hereditary renal iminoglycinuria in the probands.

In five of the seven families (Fig. 1: families 1, 2, 5, 6, and 7), both parents have persistent abnormal hyperglycinuria readily discernible by partition chromatography of urine amino acids. Quantitative studies in seven parents revealed that the renal clearance of glycine exceeded the upper limit of normal $[8.7 \mathrm{ml} /$ $\left.\left(\mathrm{min} \cdot 1.73 \mathrm{~m}^{2}\right)\right](16)$. In three parents (6.I.1, 7.I.1, and 7.I.2) only qualitative studies were obtained; nonetheless, clear evidence of hyperglycinuria was apparent. In family 4, only the father (4.I.1) had hyperglycinuria; the mother (4.I.2) had normal amino acid excretion by quantitative and qualitative methods of evaluation. In family 3 , both parents had normal amino acid excretion; however, their two offspring have hyperiminoglycinuria (Fig. 1), indicating that these "silent" parents are obligate heterozygotes for the familial renal iminoglycinuria mutation (18).

Genetic heterogeneity at the locus for familial renal iminoglycinuria is well documented (18) and it is evident even in our small sample. Mutant homozygotes of at least two different types and a genetic compound are represented in the group of seven probands. Phenotypes and simplified genotype assignments are summarized in Table 1.

\section{PLASMA CONCENTRATIONS OF AMINO ACIDS}

Elevated concentrations of either imino acid in glomerular filtrate can cause hyperiminoglycinuria through competition for reabsorption on a shared transport system (17). Proline concentrations in plasma are within the normal range for age (22) for the proband group as a whole (Fig. 2 and Table 2). Slightly elevated values were observed on one occasion, each in two probands for unknown reasons; however, the concentration of proline $(<0.8$ $\mathrm{mM}$ ) was not sufficient on either occasion to permit competitive inhibition of reabsorption as an explanation for hyperiminoglycinuria (17). The concentration of hydroxyproline in plasma was also within the normal range for age in the proband group. The same was true for glycine (Fig. 2 and Table 2).

These findings imply that the filtered load of imino acids and glycine for the proband group is normal, provided the glomerular filtration rate is also normal. Accordingly, these subjects have a selective defect in the renal tubular reabsorptive process, resulting in a specific "renal" iminoglycinuria.

\section{CREATININE CLEARANCE DATA}

We used the renal clearance of endogenous creatinine $\left(\mathrm{C}_{\mathrm{Cr}}\right)$ as an index of the glomerular filtration rate. An increase in $\mathrm{C}_{\mathrm{Cr}}$ with age was observed in the proband group (Fig. 3), which corresponds to the rise in the inulin clearance rate observed by Brodehl (4) in infants of comparable age. In this study, creatinine clearance values are slightly lower than the comparable inulin clearance values. However, we did not attempt to correct for small amounts

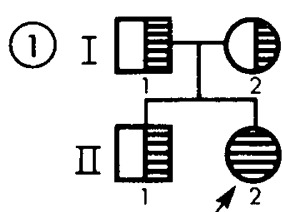

(4)
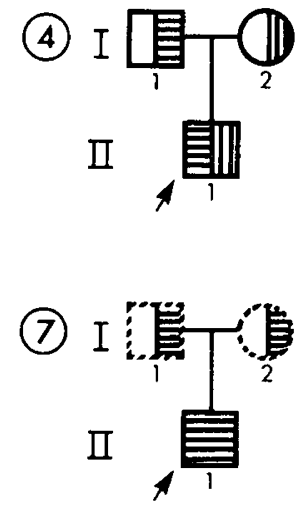

(2)

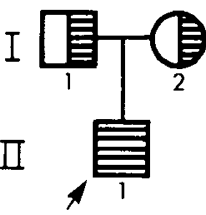

(5)

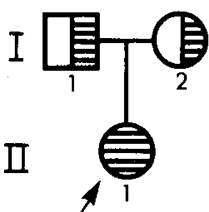

LEGEND
(3)

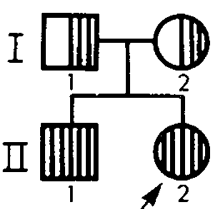

(6)

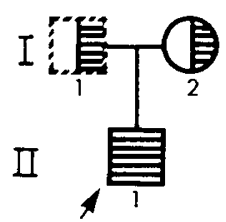

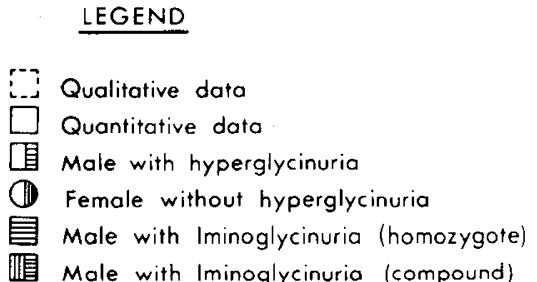

Fig. 1. Phenotypes of seven probands with renal iminoglycinuria and their first-degree relatives. Two types of parental phenotypes were found: hyperglycinuric $([\mathrm{F},(\theta)$ and normal $(\mathbb{W},(\mathbb{B})$ ), indicating different genotypes. Probands with massive iminoglycinuria are either homozygous (of two types 圈 or 自) or a genetic compound 睒 (4.II.1) on the basis of quantitative data in pedigrees. 
Table 1. Probands and family members: renal clearance of amino acids and apparent genotypes

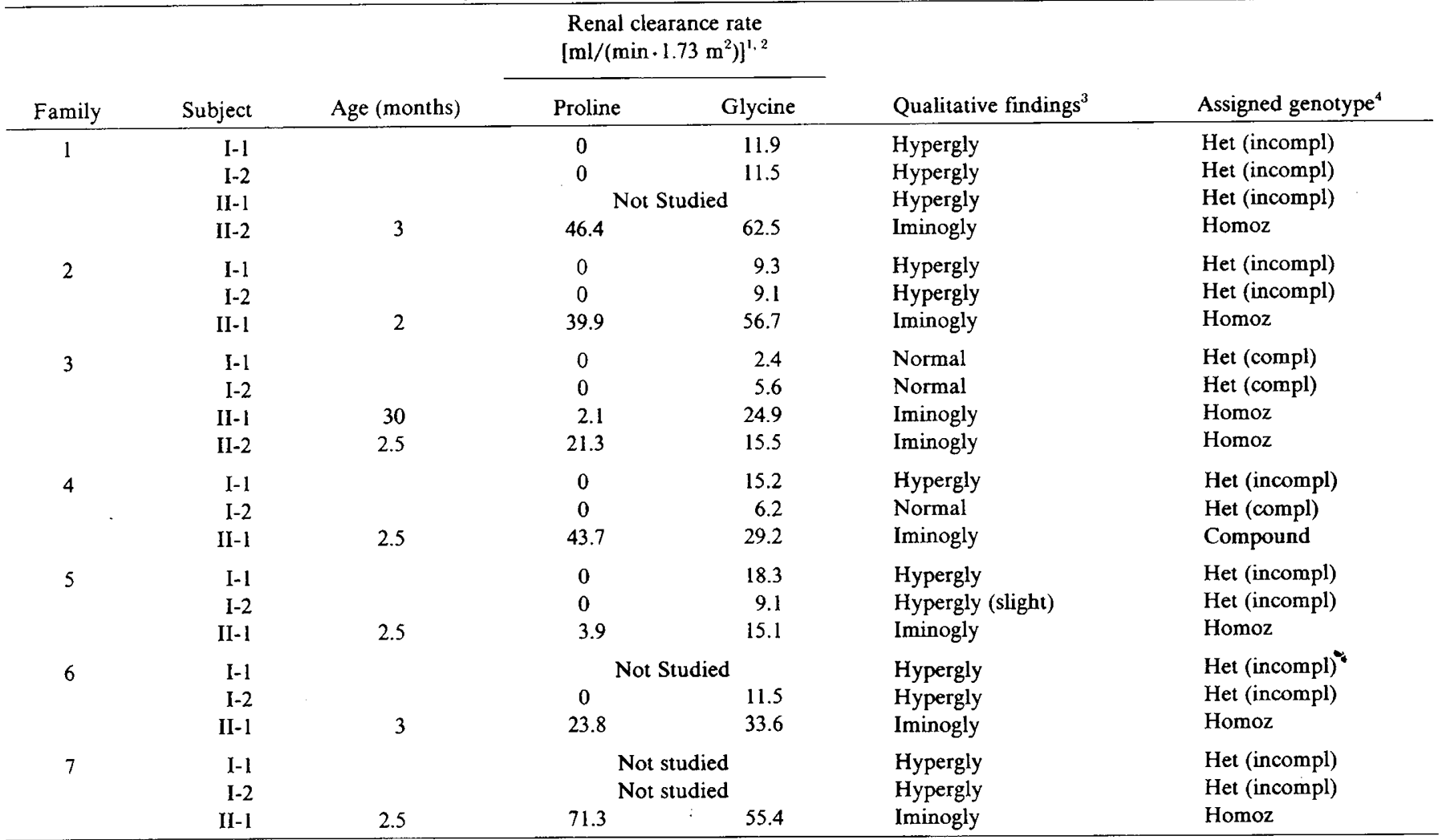

${ }^{1}$ Renal clearance rates determined in fasting state in morning with subject in supine position. Normal values $\mathrm{ml} /\left(\mathrm{min} \cdot 1.73 \mathrm{~m}{ }^{2}\right)$. Adults: proline, 0 ; glycine $<8.6$; infants:proline $<2$; glycine $<17$.

${ }^{2}$ Data for hydroxyproline not shown. All probands with abnormal proline excretion had abnormal excretion and clearance of hydroxyproline for age also.

${ }^{3}$ Partition chromatography according to method of Dent (5) applied to clearance urine and/or random urine samples. Designations indicate heavy glycine excretion alone (hypergly) or excessive excretion of proline, hydroxyproline, and glycine (iminogly).

${ }^{4}$ There are four probable mutant alleles (18); it is not possible to designate the precise form of allele without additional studies. Only simple designations (incomplete heterozygote $=$ hypergy and complete $($ compl) heterozygote $=$ normal aminoaciduria) are indicated for obligate heterozygotes . Probands are either homozygotes (two types: incomplete (incompl) $\times$ incompl or compl $\times$ compl) or genetic compounds.

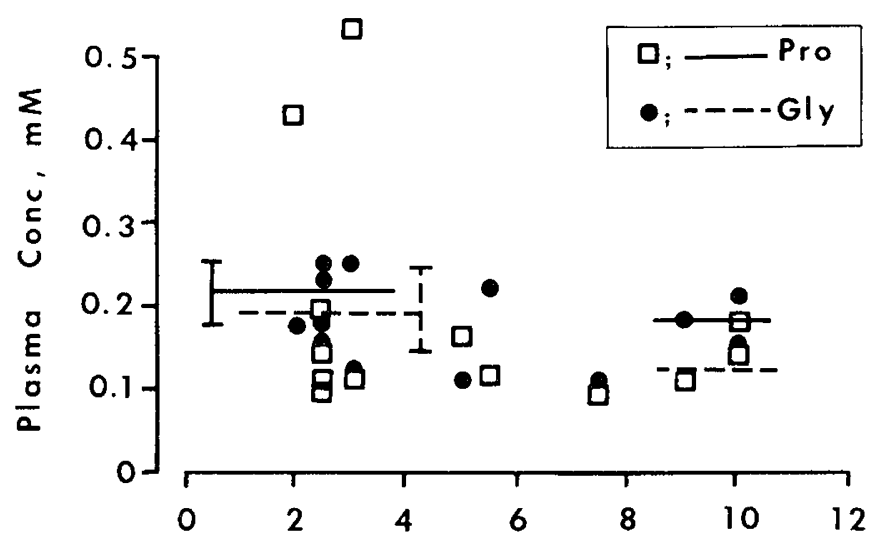

Age, months

Fig. 2. Concentration of proline and glycine in plasma of probands with familial renal hyperiminoglycinuria. Mean \pm SD values shown for normal infants (data from Refs. 4 and 22).

of contaminating noncreatinine plasma chromogen detectable by the analytical method employed in our investigation.

Brodehl (4) collected urine by an indwelling catheter; urine was voided spontaneously in our patients. Although our protocol is less precise, it seems not to have compromised the observations obtained for our group of probands.

\section{RENAL CLEARANCE AND FRACTIONAL EXCRETION OF PROLINE AND GLYCINE}

Whereas renal clearance of other amino acids was comparable to that observed in normal infants, clearance of imino acids and glycine was greatly elevated at the initial observation in all seven probands (Table 2). When fractional excretion is calculated, $F_{\text {Pro }}$ and $F E_{\text {Gly }}$ are both well above the age-specific normal range (Fig. 4). Some values for FE approach 1.0, indicating that fractional reabsorption (FR $=1-\mathrm{FE}$ ) of the relevant amino acid is almost totally deficient.

$A$ decline in $\mathrm{FE}_{\mathrm{Pro}}$ and $\mathrm{FE}_{\mathrm{Gly}}$ occurred with age during the first year of life in the proband group, but normal values (zero for proline; $<0.05$ for glycine (Ref. 4 )) were not attained by the group in the age period beyond 6 months. Calculation of the regressions for $\mathrm{FE}_{\mathrm{Pro}}$ and $\mathrm{FE}_{\mathrm{Gly}}$ versus age revealed that net reabsorption for proline and glycine, respectively, changed independently in the probands; proline reabsorption improved earlier than glycine reabsorption. These findings, presented as percentage of reabsorption of filtered proline and glycine $[(1-\mathrm{FE} \times 100)]$ are shown in Figure 5; ontogeny of tubular reabsorption for proline and glycine by 12 and 13 normal infants, respectively, as determined by Brodehl (4), is shown on the same graph. 
Table 2. Renal clearance of proline and glycine by infants with familial renal iminoglycinuria

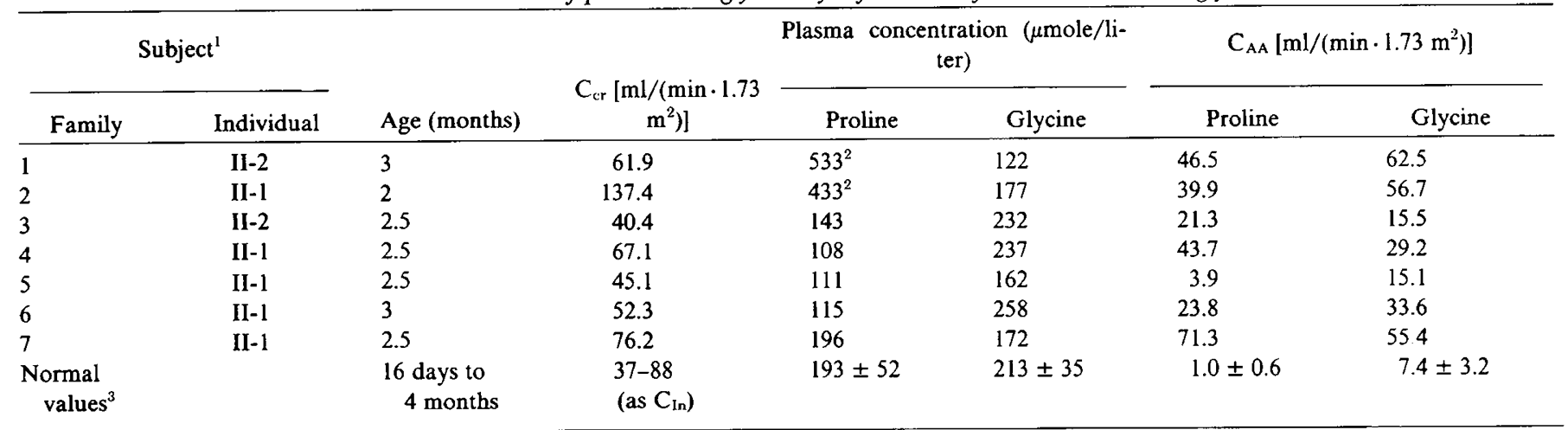

\footnotetext{
' Probands as shown in Figure 1; all subjects are presumed homozygotes or genetic compounds.

${ }^{2}$ Exceptional temporary values; findings at later age in normal range (see Fig. 3 ).

${ }^{3}$ From Brodehl (4); range or mean \pm SD shown.
}

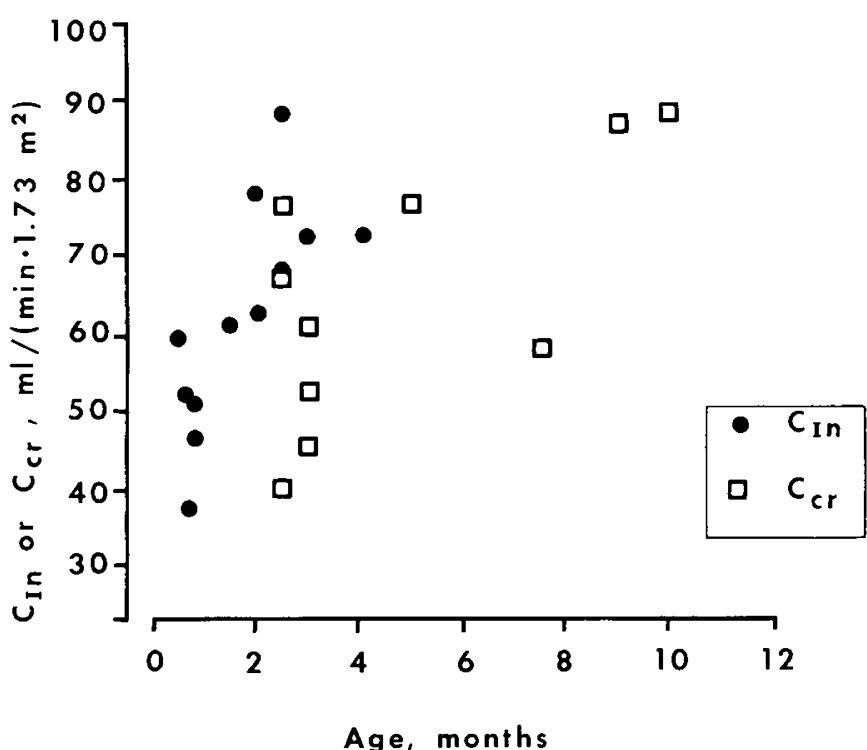

Fig. 3. Age-dependent renal clearance of endogenous creatinine $(\square)$ in seven probands with familial renal iminoglycinuria. Data for inulin clearance by normal infants [from Brodehl (4)] shown for comparison.

\section{DISCUSSION}

Selective hyperexcretion of the imino acids and glycine occurs after the early newborn period in two known situations: either when mutation or acquired circumstances cause the filtered load of one imino acid to increase so that competitive inhibition occurs on a shared system, thus impairing net reabsorption of the other imino acid and glycine (17), or when mutation causes a shared system to have deficient activity (18). Our seven infants have essentially normal concentration of amino acids in plasma, thus eliminating the first interpretation. The family data indicate that an autosomal gene segregating in the probands and affecting tubular reabsorption of imino acids and glycine accounts for their hyperiminoglycinuria.

We have assigned homozygous (or compound) status to each proband (Fig. 1 and Table 1 ). We believe this is appropriate on the basis of the quantitative data. By comparison, an obligate heterozygous infant studied at 5 months of age (27) had no iminoglycinuria and only modest hyperglycinuria; at a comparable age, our subjects all had hyperprolinuria and more severe hyperglycinuria. Absence of prolinuria was observed on one occasion in one proband at 10 months of age (subject 2.II.1). This finding is still compatible with homozygous deficiency of the transport system shared by imino acids and glycine. If the alternate proline transport system is intact and if plasma proline is below $0.15 \mathrm{mM}$, prolinuria can be absent in the mutant homozygote (16). Such conditions prevailed in the proband on that particular occasion.

Evidence for more than one type of transport system serving transport of imino acids and glycine in mammalian kidney has been found by many investigators. The presence of a significant residual transport activity with unusual characteristics in mutant homozygotes, unmasked by the deletion of the proposed shared system, was the first indication for heterogeneity of transport mechanisms for imino acids and glycine in human kidney $(16,18$, 24). Subsequent studies with thin cortex slices prepared from rat (13) and human kidney (9) revealed the presence of more than one transport mediation for renal uptake of imino acids and glycine. Similar findings were obtained from isolated rabbit renal tubule segments $(7,8)$. In regard to the polarity of solute entry in renal epithelial cells during reabsorption in vivo, the relevant net flux occurs at the brush border membrane $(20,23)$, but in the slice the orientation of the major route of entry may occur predomi-

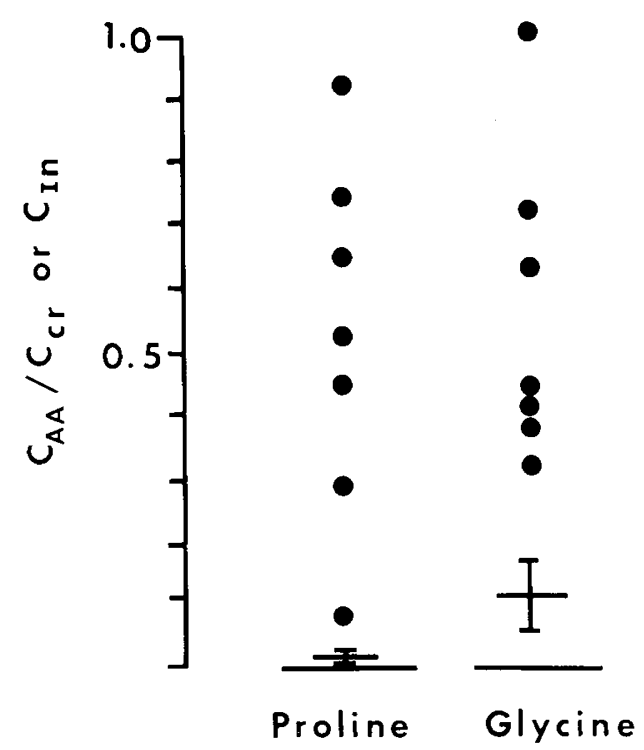

Fig. 4. Fractional excretion of proline and glycine (expressed as $C_{A A} /$ $\mathrm{C}_{\mathrm{C}_{r}}$ ) in seven probands with familial renal iminoglycinuria, at time of first quantitative study (between 2 and 3 months old). Control data [from Brodehl (4)] for infants up to 4 months old shown as mean \pm SD at bottom of columns. 

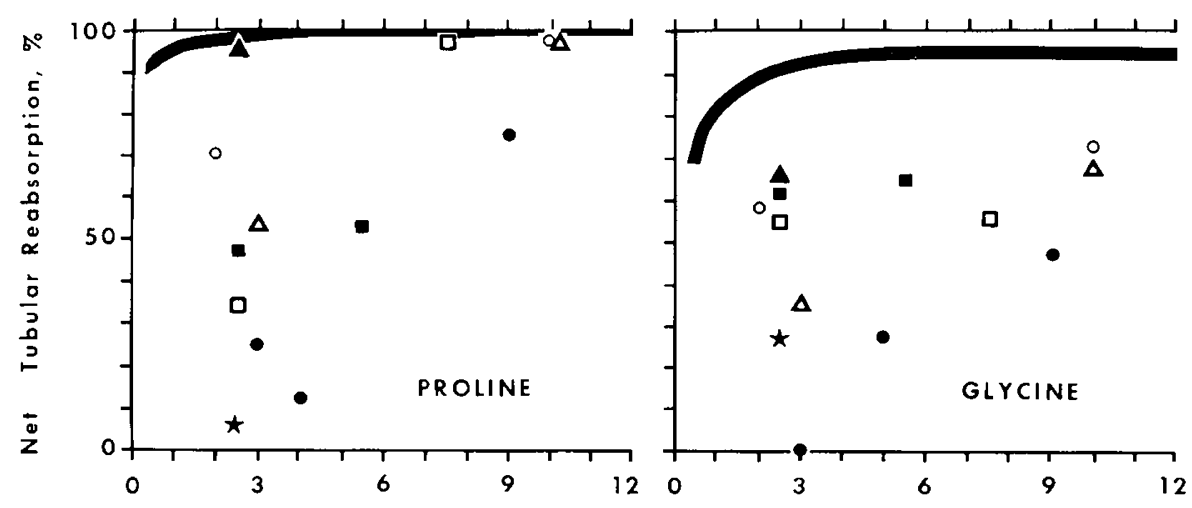

Age, months

Fig. 5. Tubular reabsorption of proline and glycine in relation to age in seven probands with familial renal iminoglycinuria. Shaded area indicates tubular reabsorption by normal infants [from Brodehl (4)]. Symbols indicate respective probands: 1.II.2, ๑; 2.II.1, O; 3.II.1, $\mathbf{\square} ; 4 . I I .1, \square ; 5 . I I .1, \mathbf{4} ;$ 6.II.1, $\triangle ;$ 7.II.1, $\star$.

nantly at the basolateral membrane $(20,26)$. Therefore, in vivo (reabsorption) and in vitro (uptake) studies may not inform us about the same topologic process of uptake.

There is general agreement from studies with isolated brush border membranes $(6,12)$ that at least two systems serve proline and glycine transport in mammalian kidney. These findings are concordant with the aforementioned observations. However, there is disagreement as to the specific characteristics of the various transport systems when comparative delineation of exclusive and shared systems is attempted. However, the brush border membrane, slice, and tubule studies were performed on different species (rabbit and rat) and variation between species may be a real factor. Accordingly, our human data may not conform to predictions derived from nonhuman data.

One way to characterize the diversity of transport systems for the imino acids and glycine in human kidney is to examine the newborn infant who is homozygous (or a genetic compound) for familial renal iminoglycinuria, while renal function is maturing. We have now done this. There is unequivocal quantitative evidence $(4,14)$ for immaturity of the process sustaining net reabsorption of imino acids and glycine in the normal newborn infant, and there is qualitative evidence $(22,28)$ for a schedule of maturation of transport processes. Hyperiminoaciduria subsides during the first 3 months of life while hyperglycinuria persists for about 6 months in the normal infant; diminishing urinary excretion largely reflects improving tubular reabsorption.

If one proposes that the process of ontogeny reflects maturing activity of independent low-capacity transport systems for the imino acids and glycine and that the autosomal mutant gene affects yet another shared high-capacity transport system, a prediction can be made concerning the phenotype of the mutant homozygous newborn. Such an individual deficient in both systems controlled by ontogeny and lacking the system affected by mutation should have a profound deficiency of net tubular reabsorption, so that urinary excretion of imino acids and glycine on occasion might even equal the filtered load. Our findings fulfill this prediction quite well. If there are independent residual systems for proline and glycine reabsorption each with their own schedule of maturation, and assuming the normal schedule of ontogeny is retained by mutant subjects, hyperiminoaciduria should subside first in the mutant infant homozygote, and hyperglycinuria should subside more slowly, reaching the level of the mature mutant homozygote at a later age. The data obtained from the seven iminoglycinuria probands indicate a postnatal profile of maturing transport activity similar to the predicted profile.

Our findings in a human condition, where the ontogeny of selective systems for net tubular reabsorption of proline and glycine can be observed in isolation, are concordant with earlier studies in the rat from our laboratory (1-3). For reasons still under investigation, they are not so with respect to similar studies in the rat by Segal's group (S. Segal, personal communication, 1977). Unfortunately, our findings do not yet inform us whether the observed schedule of ontogeny reflects appearance of membrane carrier activity along the length of the proximal tubule, where amino acid reabsorption occurs $(11,19)$, or only in the proximal tubule adjacent to the glomerulus where the low- $K_{m}$ (high-affinity) amino acid carriers may reside preferentially (11). Nor do they eliminate the possibility that lengthening of the proximal tubule during ontogeny is necessary for improved efficiency of glycine reabsorption, rather than the emergence of specific sites in the region occupied by the proposed independent proline sites (see discussion of Ref. 4).

\section{CONCLUSION}

The postnatal schedule of change in the fractional excretion of proline and glycine by seven infants homozygous for familial renal iminoglycinuria is compatible with the expression of three gene products in the human renal brush border membrane, each involved in a particular way with the reabsorption of imino acids and glycine. One controlled by the gene locus affected by the mutation causing familial renal iminoglycinuria is deficient in these probands, another selectively serving proline reabsorption matures early after birth by 3 months of age, and a third serving glycine reabsorption selectively matures later by 6 months of age.

\section{REFERENCES AND NOTES}

1. Baerlocher, K., Scriver, C. R., and Mohyuddin, F.: Ontogeny of iminoglycine transport in mammalian kidney. Proc. Natl. Acad. Sci. (USA), 65: 1009 (1970).

2. Baerlocher, K. E., Scriver, C. R., and Mohyuddin, F.: The ontogeny of amino acid transport in rat kidney. I. Effect on distribution ratios and intracellular metabolism of proline and glycine. Biochim. Biophys. Acta, 249: 353 (1971).

3. Baerlocher, K. E., Scriver, C. R., and Mohyuddin, F.: The ontogeny of amino acid transport in rat kidney. II. Kinetics of uptake and effect of anoxia. Biochim. Biophys. Acta, 249: 364 (1971).

4. Brodehl, J.: Postnatal development of tubular amino acid reabsorption. In: S. Silbernagl, F. Lang, and R. Gregor: Amino Acid Transport and Uric Acid Transport, p. 128 (Georg Thieme Verlag KG, Stuttgart, 1976).

5. Dent, C. E.: A study of the behaviour of some sixty amino acids and other ninhydrin reacting substances on phenol-"collidine" filter paper chromatograms with notes as to the occurrence of some of them in biological fluids. Biochem. J., 43: 169 (1948).

6. Hammerman, M. R., and Sacktor, B.: Transport of amino acids in renal brush border membrane vesicle. J. Biol. Chem., 252: 591 (1977).

7. Hillman, R. E., Albrecht, I., and Rosenberg, L. E.: Identification and analysis of multiple glycine transport systems in isolated mammalian renal tubules. J. Biol. Chem., 243: 5566 (1968).

8. Hillman, R. E., and Rosenberg, L. E.: Amino acid transport by isolated mammalian renal tubules. II. Transport systems for L-proline. J. Biol. Chem., 244: 4494 (1969). 
9. Holtzapple, P., Genel, M., Rea, C., and Segal, S.: Metabolism and uptake of Lproline by human kidney cortex. Pediatr. Res., 7: 818 (1973).

10. Laberge, C., Scriver, C. R., Clow, C. L., and Dufour, D.: Le Réseau de Médecine Génétique du Québec. Un programme intégré de diagnostic, conseil et traitement des maladies métaboliques héréditaires. L'Un. Méd. Canada, 104: 428 (1975).

11. Lingard, J., Rumrich, G., and Young, J. A.: Amino acid reabsorption in various sections of the rat nephron. Pfluegers Arch. Eur. J. Physiol., 342: 13 (1973).

12. McNamara, P. D., Ožegović, B., Pepe, L. M., and Segal, S.: Proline and glycine uptake by renal brush border membrane vesicles. Proc. Natl. Acad. Sci. USA, 73: 4521 (1976)

13. Mohyuddin, F., and Scriver, C. R.: Amino acid transport in mammalian kidney: multiple systems for iminoacids and glycine in rat kidney. Am. J. Physiol., 219: 1 (1970)

14. O'Brien, D., and Butterfield, L. J.: Further studies on renal tubular conservation of free amino acids in early infancy. Arch. Dis. Child., 38: 437 (1963).

15. Scriver, C. R.: Hereditary aminoaciduria. Prog. Med. Genet., 2: 83 (1962).

16. Scriver, C. R.: Renal tubular transport of proline, hydroxyproline and glycine. III. Genetic basis for more than one mode of transport in human kidney. J. Clin. Invest., 47: 823 (1968).

17. Scriver, C. R.: Disorders of proline and hydroxyproline metabolism. In: J. B Stanbury, J. B. Wyngaarden, and D. S. Frederickson: The Metabolic Basis of Inherited Disease, 4th edition, chap. 17, p. 336 (McGraw-Hill Book Co., New York, 1977).

18. Scriver, C. R.: Familial iminoglycinuria. In: J. B. Stanbury, J. B. Wyngaarden, and D. S. Frederickson: The Metabolic Basis of Inherited Disease, 4th edition, p. 1593 (McGraw-Hill Book Co., New York, 1977).

19. Scriver, C. R., and Bergeron, M.: Amino acid transport in kidney. The use of mutation to dissect membrane and transepithelial transport. In: W. L. Nyhan: Heritable Disorders of Amino Acid Metabolism, p. 515 (John Wiley and Sons, Inc., New York, 1974).

20. Scriver, C. R., Chesney, R. W., and McInnes, R. R.: Genetic aspects of renal tubular transport. Diversity and topology of carriers. Kidney Int., 9: 149 (1976).
21. Scriver, C. R., Clow, C. L., and Lamm, P.: Plasma amino acids: screening quantitation and interpretation. Am. J. Clin. Nutr., 24: 876 (1971)

22. Scriver, C. R., and Rosenberg, L. E.: Amino acid metabolism and its disorders. Chapt. 3. Distributions of Amino Acids in Body Fluids, chap. 3, p. 39 (W. B. Saunders Co., Philadelphia, 1973).

23. Scriver, C. R., Stacey, T. E., Tenenhouse, H. S., and MacDonald, W. A.: Transepithelial transport of phosphate anion in kidney. Potential mechanisms for hypophosphatemia. Adv. Exp. Med. Biol., 81: 55 (1977).

24. Scriver, C. R., and Wilson, O. H.: Amino acid transport in human kidney: evidence for genetic control of two types. Science, 155: 1428 (1967).

25. Shapcott, D., Lemieux, B., and Sahapoglu, A.: A semi-automatic device for multiple sample application to thin-layer chromatography plates. J. Chromatogr., 70: 174 (1972).

26. Wedeen, R. P., and Weiner, B.: The distribution of $p$-aminohippuric acid in rat kidney slices. 1. Tubular localization. Kidney Int., 3: 205 (1973)

27. Whelan, D. T., and Scriver, C. R.: Cystathioninuria and renal iminoglycinuria in a pedigree. A perspective on counseling. N. Engl. J. Med., 278: 924 (1968).

28. Woolf, L. I., and Norman, A. P.: The urinary excretion of amino acids and sugars in early infancy. J. Pediatr., 50: 271 (1957).

29. Presented in part at the Plenary Session of the Annual Meeting of the American Pediatric Society, New York, April 1978.

30. We are grateful to Mlle Jacqueline Rioux and her colleagues in the Clinical Investigation Unit of the Montreal Children's Hospital for their excellent assistance with the renal clearance studies. Dr. Bernard Lemieux, director of the QNGM center at Centre Hospitalier Universitaire, Sherbrooke, kindly referred the patients. The assistance of Carol Clow and Susan Mackenzie in these investigations is greatly appreciated.

31. This research was supported by the Quebec Network of Genetic Medicine and by a grant from the Medical Research Council of Canada to the MRC Group in Medical Genetics at McGill University.

32. Received for publication December 12, 1977.

33. Accepted for publication March 2, 1978. 